\title{
Performance Enhancement of TMT Rebar in Accelerated Corrosion
}

\author{
Akshatha Shetty ${ }^{1, *}$, Katta Venkataramana ${ }^{1}$, Indrani Gogoi ${ }^{2}$, Praveen B. B ${ }^{1}$ \\ ${ }^{1}$ Department of Civil Engineering, NITK, Surathkal.Srinivasnagar, 575025, India \\ ${ }^{2}$ Assam Engineering Institute Chandmari, 781003, Guwahati
}

\begin{abstract}
Thermo-Mechanically-Treated (TMT) bars have recently been used as advancement over the conventional mild steel bars in reinforced concrete structures in order to enhance the durability in corrosive environment. Corrosion of steel reinforcement leads to cracking of reinforced concrete sections and thus may further reduce the load carrying capacity and serviceability of the structural members. Corrosion of rebars may cause reduction in yield strength of steel, affect the bond strength due to delamination of rust formed on the rebar surface. In this paper, the results of an experimental investigation on effects of corrosion on the mechanical strength of TMT steel rebars are presented. Corrosion is induced on the bars by impressed current method. The rebars are subjected to varying levels of corrosion and their stress strain characteristics are studied. The stress strain characteristics indicate a decrease in the area under stress strain curve with increasing level of corrosion. Further, it is observed that the yield strength of steel bars is not affected at a lower percentage of corrosion, but for higher percentage of corrosion there is a considerable reduction in yield strength, percentage of elongation. It was also observed that at a higher percentage of corrosion the failure pattern of bars had changed from ductile mode to brittle mode.
\end{abstract}

Keywords Thermo-Mechanically-Treated (TMT), Yield Strength, Corrosion, Ductile, Brittle, Deterioration

\section{Introduction}

Reinforced concrete structures exposed to marine environment are subjected to simultaneous action of number of physical chemical and electro chemical deterioration process. In the view of immense cost involved in initial construction and in repair and rehabilitation, it is quite important that these structures should able to resist the ravages of time and deleterious effects of harsh environmental condition with minimum maintenance cost and hence reinforcement corrosion has been identified as the predominant deterioration mechanism for reinforced concrete structures, which seriously affects the serviceability and the safety of the structures.

It has long been recognized that carbon steel reinforcing bars have a low resistance to corrosion in chloride-bearing environments, resulting in many and marine structures having been severely damaged by corrosion of the reinforcement. Although concrete provides protection for embedded steel, the penetration of oxygen, water and chloride to the carbon steel allows rapid deterioration of the entire structure (Castro, 2003). An easy way to overcome the problem of

* Corresponding author:

akshathashetty16@gmail.com (Akshatha Shetty)

Published online at http://journal.sapub.org/jce

Copyright (C) 2012 Scientific \& Academic Publishing. All Rights Reserved corroding carbon steel, which leads to reinforced concrete failure, structural problems and costly repairs, is to replace the reinforcing carbon steel with reinforcement produced with highly corrosive resistant materials or metal alloys.

Technological advances during the last few years in the field of deformed bar production steel manufacturing industry has successfully developed a corrosion-resistant variety of rebar for the construction industry. This type of steel, called thermo-mechanically treated (TMT), which imparts the better corrosion resistance against severe environment conditions. In the TMT process the hot rebars emerging out of the final rolling stand are subjected to rapid on-line cooling through a series of water jackets. Direct water quenching results in the formation of martensite at the surface layers of the rebars, while the core remains austenitic. The thermal gradient existing across the rebar section emerges from the quenching zone causes heat to flow from the hot austenitic core toward the rebar surface. This results in the tempering of the surface martensite, and an equalization of the surface and core temperatures takes place. Lower equalization temperatures result in higher yield strengths. During subsequent atmospheric cooling of the rebar on the cooling bed, the hot austenitic core gradually transforms to a ferrite-pearlite microstructure. This composite structure, in which the rim of the tempered martensite acts as the load-bearing constituent and the relatively soft ferrite-pearlite core provides the rebars with ductility and cold 
formability, helps in imparting superior mechanical properties to TMT rebars compared to the conventionally used carbon steel rebars (Ray,1997).

In the present work, the most serious mechanisms leading to steel corrosion are shortly presented. Some of the effects of the steel corrosion on the mechanical properties of the reinforcing bars are experimentally measured using accelerated tests on bare bars in laboratory conditions. The tensile properties of the corroded material were compared against the non corroded bars. The present investigation will contribute towards the modeling of the corrosion deterioration, and thus to the quantitative approach of the residual strength and service life of structural elements.

\section{Effect of Corrosion on Mechanical Properties of Steel}

Experimental results shows that bars subjected to accelerated corrosion shows significant loss in strength and ductility. Results from the accelerated corrosion tests on bare steel bars are in a good qualitative agreement with results from steel bars embedded in aged concrete (Apostolopoulos, 2009). As severity of corrosion on the on the tensile behavior of reinforcing steel bars reduces the cross sectional area and load carrying capacity of the rebars results in the increase of the stress applied to the bars as loads of a reinforced concrete structures remains constant throughout service life of the structure. The reduction in the sectional properties of the rebars decreases the moment of inertia which results in the decreased buckling strength of rebars.

\section{Experimental Program}

Three pre-corroded TMT rebars of $20 \mathrm{~mm}$ nominal diameter and each $600 \mathrm{~mm}$ length from each percentage of corrosion were subjected to the tensile test and the mean values are reported. For the tensile tests, a Universal Testing Machine of capacity $250 \mathrm{kN}$ was used. The deformation rate was $2 \mathrm{~mm} / \mathrm{min}$. The tensile properties, yield stress, ultimate stress, and elongation to failure were evaluated. In this experiment the electrochemical corrosion technique is used to accelerate the corrosion of steel bars (Ahmad, 2009). To simulate the corrosion process, direct current is impressed on the bar using an integrated system incorporating a DC rectifier with a built-in ammeter to monitor the current and a potentiometer to control the current intensity with an output of $64 \mathrm{~V}$ and $10 \mathrm{amps}$ to monitor the current. To simulate deceing salt application a $5 \%$ sodium chloride solution was used as an electrolyte. The direction of current was arranged so that the steel bars served as the anode, while stainless steel plate positioned in the solution served as cathode as shown in Fig.1. To obtain the desired levels of reinforcement corrosion, the current intensity and the electrifying time had to be controlled. After desired degree of reinforced corrosion was obtained, the rebars were cleaned with acetone solution to remove the corrosion products according to ASTM G1-03 to measure the degree of corrosion as a gravimetric mass loss. After knowing degree of corrosion the rebars were tested in tension to evaluate their mechanical properties.

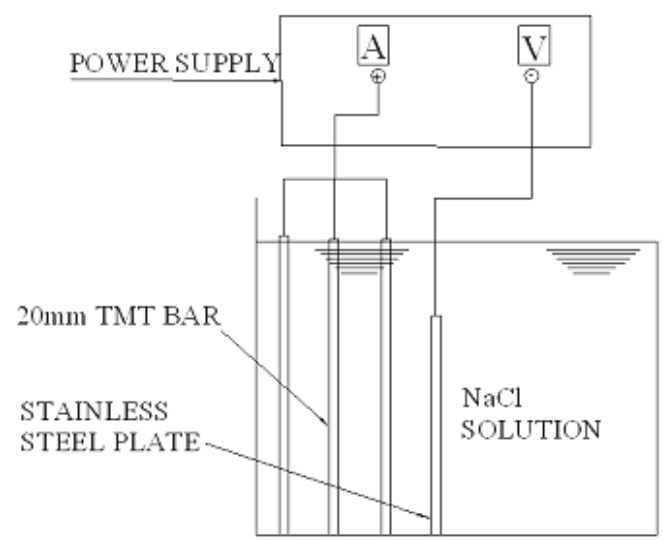

Figure 1. Schematic representation of accelerated corrosion set up

The load and elongation data were recorded till failure of the specimen, at pre-determined load intervals. The data so obtained were utilized to plot stress strain diagrams for each of the tested specimens. The yield and tensile strength of the steel bars were determined from the stress strain curves so plotted, since there was no definite yield point obtained yield strength is calculated as $0.2 \%$ proof stress. The elongation of the specimen was measured after breaking of the tensile test specimen and it was expressed as a percentage of the original gauge length to calculate percentage of elongation. The tensile tests were conducted on both corroded and non-corroded reinforcing steel bars so that the influence of degree of reinforcement corrosion on the tensile properties of reinforcing steel bars could be assessed.

\section{Results and Discussion}

\section{Mechanical Properties}

Fig. 2 shows the typical stress strain diagrams of $20 \mathrm{~mm}$ diameter TMT bars for different degrees of corrosion. From the stress strain diagram we can observe that the area under the stress strain curve is reduced with increase in the degree of corrosion. Variation of Modulus of elasticity of the rebars with respect to the degree of corrosion is insignificant as the initial linear portion of the stress strain curve is not changed adversely.Table. 1 depicts the tensile strength data for $20 \mathrm{~mm}$ diameter bar with different percentage of reinforcement corrosion. It should also be noted that even after degradation of the bars due to corrosion their tensile strength is more than designated minimum yield strength. Table. 1 also shows the yield strength of bars calculated using the nominal diameter, falls below the minimum designated yield value i.e. $415 \mathrm{MPa}$, when the degree of reinforcement corrosion is $9.8 \%$ and above. It is observed that the actual load carried by the bars, decreased with increasing level of reinforcement corrosion (Fig.3). 


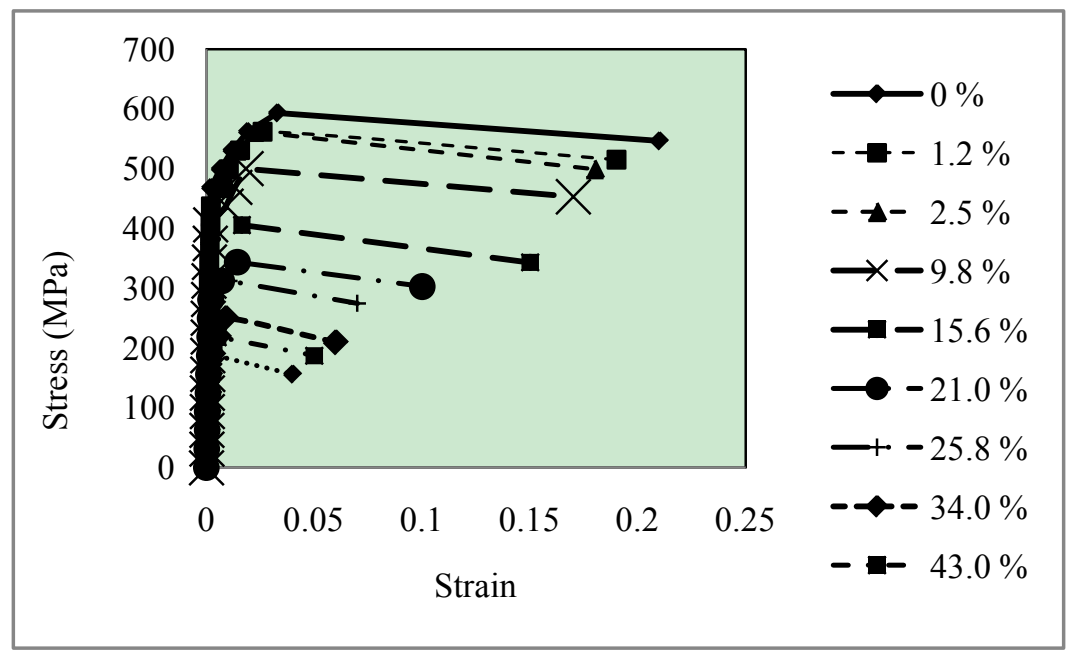

Figure 2. Stress strain curves of TMT bars with different degree of Corrosion

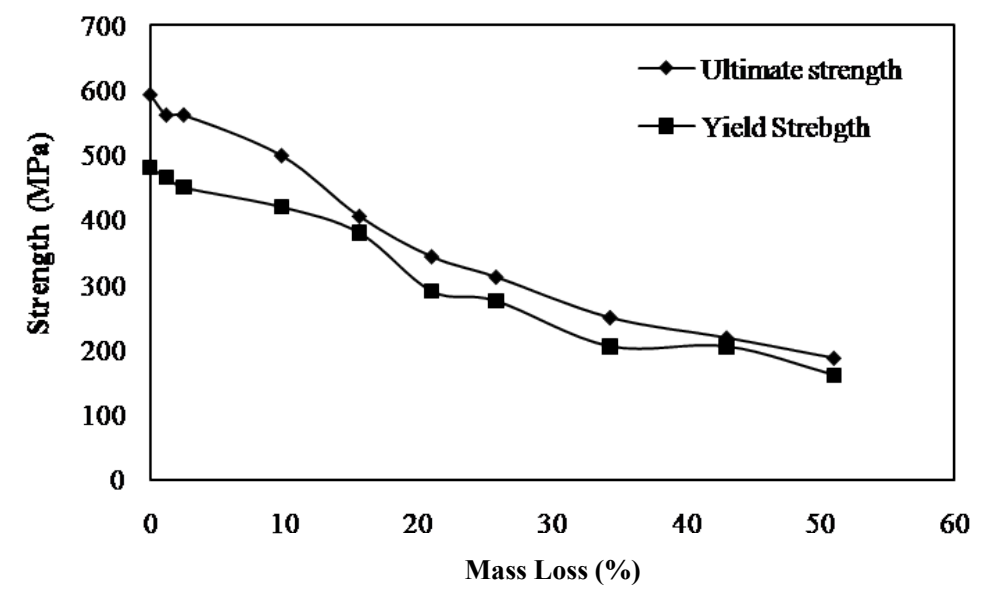

Figure 3. Effect of corrosion on $20 \mathrm{~mm}$ TMT Bars

Table 1. Tensile strength of $20 \mathrm{~mm}$ diameter TMT Bars

\begin{tabular}{|c|c|c|c|c|c|}
\hline Mass loss (\%) & $\begin{array}{c}\text { Yield Strength } \\
(\mathrm{MPa})\end{array}$ & $\begin{array}{c}\text { Percentage Reduction } \\
\text { in Yield Strength }\end{array}$ & $\begin{array}{c}\text { Ultimate } \\
\text { Strength (MPa) }\end{array}$ & $\begin{array}{c}\text { Percentage Reduc- } \\
\text { tion in Ultimate } \\
\text { Strength }\end{array}$ & $\begin{array}{c}\text { Percentage of } \\
\text { elongation }\end{array}$ \\
\hline 0.0 & 480 & & 593.29 & 5.20 & 21.0 \\
\hline 1.2 & 465 & 3.12 & 562.07 & 5.20 & 19.0 \\
\hline 2.5 & 450 & 6.20 & 562.07 & 10.52 & 17.0 \\
\hline 9.8 & 420 & 12.50 & 499.61 & 31.50 & 15.0 \\
\hline 15.6 & 380 & 20.80 & 405.94 & 36.80 & 10.0 \\
\hline 21.0 & 290 & 39.50 & 343.84 & 47.36 & 7.0 \\
\hline 25.8 & 275 & 42.70 & 312.26 & 57.89 & 6.0 \\
\hline 34.3 & 205 & 57.29 & 249.80 & 63.15 & 5.0 \\
\hline 43.0 & 205 & 57.29 & 218.58 & 68.42 & 4.0 \\
\hline 51.0 & 161 & 66.40 & 187.35 & & \\
\hline
\end{tabular}

\section{Failure modes of Rebars}

It is evident from the experimental investigations that the corresponding elongation of rebars before failure is de- creased as degree of corrosion increases. The non-corroded bars showed large amount of yielding before their breaking. With increase in corrosion the yielding strain of the rebars 
reduced (Table 1) i.e, the percentage of elongation of the rebars is reduced with increase in the degree of corrosion, which implies that corrosion of reinforcement increases its brittleness. Reinforcing steel bars with $9.8 \%$ or more reinforcement Corrosion indicates a brittle failure behavior as shown in the Fig.4. Also, the elongation of bars with $15.6 \%$ or more corrosion is less than that specified by IS: 1786-2008, i.e. $14.5 \%$.

The surface characteristics of rebars changed with degree of corrosion. The surface of the rebar roughened with continuous small pits and holes on the surfaces. The depth of the pits increased with increase in the degree of corrosion. Rebar's with $15.6 \%$ or more corrosion formed small scales on the surface which are noticed while cleaning the bars.

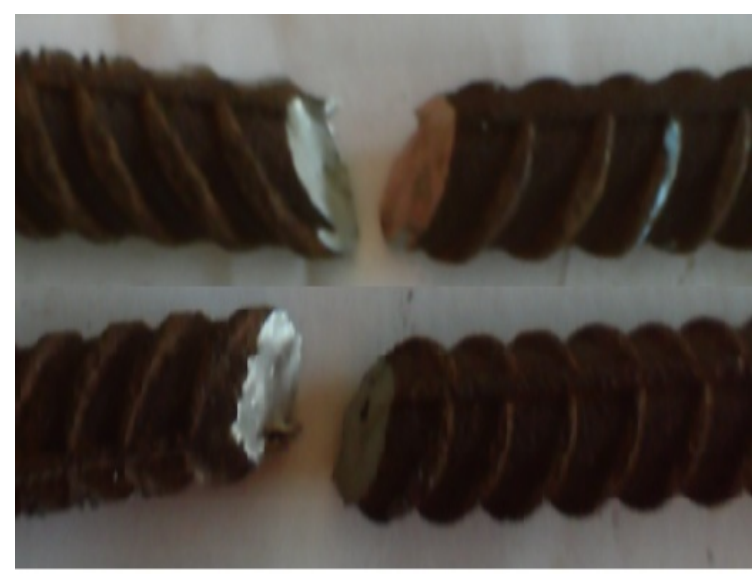

Figure 4. Brittle failure mode of Rebars

\section{Conclusions}

The mechanical properties of TMT reinforced bars were determined in relation to varying degree of corrosion the following conclusions have been finally drawn. The strength of the rebars decreased with increase in the corrosion. There is no significant variation in the modulus of elasticity of the rebars with degree of corrosion. However, the yield strength is less than minimum designated yield value when the corrosion is more than $9.8 \%$. Stress strain characteristics indicated that the yield strain value decreased with corrosion which indicates the reduction in ductility and increase in the brittleness of the rebars. The elongation of the specimens significantly decreased with corrosion, furthermore the elongation of bars with $15.6 \%$ or more corrosion is less than that specified by IS: 1786-2008. The rebars with corrosion 9.8\% and more showed brittle behavior.

\section{ACKNOWLEDGEMENTS}

The Partial financial support from BRNS research project Sanction No. 2009/36/115-BRNS/3371 dated $17^{\text {th }}$ March, 2010 is gratefully acknowledged.

\section{REFERENCES}

[1] Ahmad, (2009) "Techniques for inducing accelerated corrosion of steel in concrete", Department of Civil Engineering King Fahd University of Petroleum \& Minerals Dhahran, Saudi Arabia, The Arabian Journal for Science and Engineering, 34

[2] Apostolopoulos.C.A., Papadakis, (2009) "Consequences of steel corrosion on the ductility properties of reinforcement bar", Department of Mechanical and Aeronautical Engineering, University of Patras, Greece, Journal of Construction and Building Materials, 22, 2316-2324

[3] ASTM G1-03, (2003) "Standard Practice for Preparing, Cleaning, and Evaluating Corrosion Test Specimens", American society for Testing and materials

[4] Castro, P., Weva and Balancim, M. (1997). "Corrosion of reinforced concrete in a tropical marine environment and in accelerated tests". Journal of Construction and Building Materials, 11(2), 75-88

[5] IS 1786:2008, High Strength deformed steel bars and wires for concrete reinforcement Specification

[6] Ray. A, et al, (1997). "Microstructure and Properties of Thermo-mechanically Strengthened Reinforcement Bars: A Comparative Assessment of Plain Carbon and Low-Alloy Steel Grades", Steel Authority of India Limited, Ranchi-834002, India, Journal of materials Engineering and performance, 6(3), 335-343 